\title{
YUNAN DEVLETLER HUSUSI HUKUKU
}

\author{
Yazan: Dr. Hikmet BELBEZ
}

Yunanlılar uzun çalışmalardan sonra 1/6/1941 de yürürlüğe giren yeni ve modern bir Medeni Kanun vücuda getirdiler $\left[{ }^{1}\right]$. Yunanlilar muayyen bir devletin kanununu olduğu gibi almaktan bilerek vazgeçmis, kendi tarihî, millî ve kültürel hayatlarını uygun bir kanun yaratmayı tercih etmişlerdir $\left.{ }^{2}\right]$. Bununla beraber Fransız, Alman ve Italyan Medeni Kanunlarından büyük ölçüde istifade edilmiştir.

Yeni Yunan Medeni Kanununun birinci kitabını genel kısım, yani genel hükümler teşkil ediyor $\left[^{3}\right]$. Birinci kitabın ikinci bölümü de devletler bususi bukuku hakkındaki hükümleri ihtiva etmektedir (madde 4-33). Bütün genel kısım gibi kanunlar ihtilâfı hakkındaki bu kaidelerin esası da Yunanlıların büyük hukukģusu ve Atina Üniversitesi Ptofesörlerinden Georg S. Maridakis' in kaleminden çıkmışır $\left[{ }^{4}\right]$.

Kanunun, devletler hususi hukuku kaidelerini ihtiva eden bu kısminda Alman hukukunun tesiri bilhassa barizdir. Bu kaideler birçok bakumlardan Alman Medeni Kanununun Tatbikr hakkrndaki Kanunun 7 nci den 31 inciye kadar olan maddelerinin hükümlerine benzetilmiştir $\left[{ }^{5}\right]$.

1 Bu kanunun hazırlanması ve ana hatları hakkında bilgi edinmek için bak: lsmail Hakkı Tur, Yeni Yunan Medeni Kanunu, Adliye Ceridesi 1940 sayı 6 sahife 560 vdd.

2 Kanunu hazırlyyan komisyonun reisi Prof. Ballis'in nutku, Ísmail Hakki Tur, ayni yazı s. 560 .

3 Yeni Yunan Medeni Kanununun Fransızca tereümesi için bak: Savidis X, Le Nouveau Code Civil Hellénique, Athénes 1940.

4 Bak: Zeitschrift für Ausländisches und Internationales Privatrecht 1937, say1 $1 / 2$, sahife 111 .

5 Bu maddelerin Türkçe terçümesi için bak: Prof. Leo Raape, Fransız devletler hususi hukuku ile karşılaştırmak suretiyle Alman devletler hususi hukukunun ana hatları, Siyasi İlimler Mecmuası 1942, sayı 135, sahife 89. 
Diğer taraftan devletler hususi hukukunun birleştirilmesine dair olan Lâhey Anlaşmalarında kabul edilen esaslar da mümkün olduğu kadar göz önünde tutulmuştur $\left[{ }^{6}\right]$.

Yeni kanunun ihtiva ettiği kanunlar ihtilâfı kaidelerinin en bariz vasfı şahsi hükümler bakımından ikametgâh esasına dönülmiyerek, Yunanistanda ötedenberi olduğu gibi [ $\left.{ }^{7}\right]$ uyrukluk esasımın muhafaza edilmiş olmasıdır. Yunanistanda da şahsi statï, bizde de olduğu gibi, uyrukluk hukukuna, yani millî hukuka tâbidir.

Bu hükümlerin dikkata değer diğer bir hususiyeti de atıf müessesesinin kabul edilmemiş olmasıdır. 32 nci maddede «yabancı hukukun tatbikı lâzım gelen hallerde o yabancı devletin devletler hususi hukuku kaideleri nazarı itibara alınmaz» demekle Yunan Kanun vazı «milletlerarası tenis oyunu» na kesin olarak son vermek istemiş ve devletler hususi hukukunda atıf müessesesi etrafındaki malûm münakaşayı kökünden halletmiştir $\left[{ }^{8}\right]$.

Uyrukluk prensibinin tabiî bir neticesi olarak hukuki yeterlik, yani medeni haklardan istifade yeterliği (madde 5) ve medeni haklar istimal yeterliği (işlem yeterliği) (madde 7) hakkında da millî hukuk uygulanmaktadrr. Şu kadarki Yunanistanda yapılacak işlemler (muameleler) bakımından daraltıcı bir kayıt konmuştur: Yunanistanda, borçlar hukuku çevresine giren bir hukuki muameleyi yapan bir yabancı şayet Yunan Kanunlarma göre medeni haklarını kullanma yeterliğini haiz olursa, kendi millî hukukuna göre henüz ehil olmasa bile o muamele ile mülzem olur (madde 9). Yunanlıların eski, yani 1856 tarihli kanunlarına göre bu kayrt yalnız Yunanlılarla yapılacak işlemlere münhasırdı. Şimdi ise ister bir Yunanlı ile bir yabancı, ister iki yabancı arasında yapılsın, bu hüküm Yunanistanda yapılan ve yabancıların da iştiraki olan bütün hukuki muameleler hakkında caridir. Bu suretle de Alman Medeni Kanununun tat-

$6 \mathrm{Bu}$ anlaşmalar hakkında bilgi edinmek için bak: Mustafa Resit Belgesay, Devletler Hususi Hukukunda Adliye 1937, cilt 1, sahife 21 vdd.; beş anlaşmadan üçünün (12. haziran 1902 tarihli Lâhey Evlenme Anlaşması, 12 haziran 1902 Lâhey Boşanma ve Ayrılık Anlaşması, 12 haziran 1902 tarihli Vesayet Anlaşması) Türkçe metinleri için bak: Muammer Raşit Sevĭg, Devletler Hususi Hukuku, cilt 2, 1943, sahife 459 vdd.; Almanea metinler için bak: Makarov, Die Quellen des İternationalen Privatrechts, 1929, sahife 334 vdd., 346 vdd., 352 vdd, Karı ve Koca arasındaki şahsi ve mali münasebetler hakkındaki 17. 7. 1905 tarihli Lâhey Anlaşması, sahife 342 vdd., 17. 7. 1905 tarihli Lâhey Kısıt Anlaşması, sahife 356 vdd,

29. Ekim 1859 tarihli kanun madde 4. Ernst von Caemmerer, Internationales Personenrecht, Rechtsvergleichendes Handwörterbuch, cilt 4, sahife 342 vdd.; Makarow, Quellen, sahife 55.

8 Bu husustaki münakaşalar için bak: Muammer Rașit Seviğ, Devletler Hususi Hukuku, cilt 1, 1937, sahifa 304 vdd. 
bikı hakkındaki Kanunun 7 nci maddesinin 3 üncü fıkrasındaki hükme uyulmuş oluyor $\left[{ }^{9}\right]$.

Gaiplik karan hakkında da asıl olan millî hukukun tatbikidir (madde $6 \mathrm{fk} .1$ ). Fazla olarak gaiplik kararı usul hukuku bakımindan da pek çok güçlüklere sebebiyet verdiğinden, bir kimse hakkında gaiplik kararı vermek yetkisi de o kimsenin tâbi olduğu devletin mahkemelerine hasredilmiştir $\left\lfloor^{10}\right]$. Yunan mahkemeleri ancak istisnai olarak Yunanistanda ikametgâhı veya meskeni (konutu) yahut orada serveti bulunan yabancı hakkında gaiplik kararı verebilecektir (madde $6 \mathrm{fk}$. 2.).

Aşağı yukarı aynı esas hacır (kısıt) işlerinde de kabul edilmiştir. Kısıt hakkında millî hukuk uygulanır ve kısıt kararını ancak millî mahkemeler verebilir. Yunan mahkemeleri istisnai olarak Yunanistanda ikametgâhı bulunan yabancılar hakkında da kısıt kararı verebilirlerse de ikametgâhı bulunmamakla beraber Yunanistanda konutu veya serveti bulunanlar hakkında ancak geçici tedbirler alabilirler (madde 8). Bu suretle 17 temmuz 1905 tarihli Lâhey Kısıt Anlaşmasının esaslarının aşağı yukarı kabul edilmiş olduğu görülü̈yor $\left[{ }^{11}\right]$.

11 inci madde locus regit actum kaidesini ihtiva etmektedir $\left[^{12}\right]$. Fakat bu mutlak değildir. Bu maddede sayılan üç hukuktan birine uyulmuş olması işlemin şekil bakımından muteber sayılmasına yeter. Maddenin kabul ettiği, lex loci actus, yani işlemin yapıldığı yer hukukundan başka lex causae, yani işlemin esas bakımından tâbi olduğu hukuk ile lex patriae, yani tarafların millî hukukudur.

Evlenme hakkında da 12 haziran 1902 tarihli Lâhey Anlaşmasiyle tesbit edilen esas kabul edilmiştir: yani evlenme için aranan esasa mütaallik şartlar bakımından nişanlılardan her birinin millî hukuku nazarı itibara alınacaktır. Evlenmenin şekli yine locus regit actum kaidesine tâbidir. Karı ve kocanın şahsi ve malî münasebetleri hakkında da en yeni telâkilere uygun hükümler konmuştur (madde 13, 14, 15).

9 AlMK. tatbikat K. M. 7 fk. 3: bir hukuki muameleyi yapmak hususunda işlem yeterliğini haiz olmiyan veya bu husustaki yeterliği tahdid edilmiş bulunan bir yabaneı Almanyada böyle bir işlemi yaparsa, Alman kanunlarına.göre işlem yeterliğini haiz olduğu takdirde, o hukuki muameleyi yapmak hususunda ehil sayılır.

10 Bustamante Kodu madde 78.80 , gaibin milli hukukunu uygulamakla beraber bu yetkiyi herhangi bir devletin mehkemelerine tanumaktadır. Antonio Sanchez de Bustamante Sirøen, Hukuku hususiyei düvel kanun projesi, Adliye Vekâleti neşriyatından, 1930, sahife 37.

11 Makarov, Quellen, sahife 357.

12 Ayni esas 1856 tarihli kanunda da caridi, madde 7. Makarov, Quellen, sahifo $55 / 56$. 
Boşanmaya gelince, kanunun Maridakis tarafnıdan hazırlanmış bulunan tasarısında (madde 21) Lâhey znlaşmasındaki esas kabul edilmişti $\left.{ }^{13}\right]$. Buna göre boşanma sebebi olarak ileri sürülen sebebin karı ve kocanın millî hukukundan başka dâvaya bakan mahkemenin kanunlarında da boşanma sebebi olarak kabul edilmiş olması lâzımdır. Ayni esas Alman Medeni Kanununun tatbikı hakkindaki Kanunda da ifadesini bulmuştur $\left[^{14}\right]$. Yeni Yunan Kanununda ise bu esas terk edilmiştir (madde 16).

Borçlar bukuku sahasında akitten doğan borçlar için açık olarak irade mubtariyeti prensipi kabul edilmiştir. Taraflar bir akdi hangi hukuka tâbi tutarlarsa, o akte o hukuk tatbik edilecektir. Yunan kanun koyucusu bu suretle irade muhtariyeti aleyhtarlarının görüşlerine iştirak etmediğini ifade etmiş ve tatbikatta ötedenberi yerleşmiş bulunan esastan ayrılmamış, bilâkis bu hususta o kadar ileri gitmiştir ki, meselâ Polonya Kanununda olduğu gibi $\left[{ }^{15}\right]$ tarafların irade muhtariyeti dâhilinde seçebilecekleri hukukları tahdidetmemiş, diledikleri hukuku seçmek hususunda onları tamamiyle serbest birakmıştır (madde 25). Taraflar bu hukuku sarahaten veya zımnen göstermiş olabilirler. Fakat tarafların ne sarih ve ne de zımni iradelerini tesbite imkân olmadığı takdirde Yunan yargıcı artık, irade muhtariyeti taraftarlarının umumiyetle ileri sürdükleri gibi, onların mevhum ve mefruz iradelerini bulmaya, yani «taraflar bir hukuk nizamını seçmeyi düşünmüş olsalardı, hangi hukuku seçmiş olurlardr?» sualine cevap vermeye çalısmryacak, halin icaplarına göre o borç münasebeti için en elverişli olan hukuku kendisi tâyin edecek, o borç münasebetinin ağırlık merkezini, ona en yakın olan hukuku bulmaya çalışacak ve onu tatbik edecektir (madde 25). Bu hukuk, akdin yapıldığı veya yürütüleceği yerin hukuku, tarafların tâbi oldukları devletin veya ikametgâhlarının bulunduğu yerin hukuku veya diğer her hangi bir hukuk olabilir.

Haksız fiillerden doğan - borçlar hakkında lex loci delicti commitssi, yani haksız fiilin işlendiği yerin hukukunun tatbikı kabul edilmiştir (madde 26). Bu yeni kanunda çok önemli bir değişikliktir. Şimdiye kadar Yunanistanda haksiz fiillere daima Yunan kanunlart tatbik

13 12. hazirn 1902 tarihli Lâhey anlaşması madde 1. Muammer Raşit Seviğ, adı geçen eser cilt 2 , sahife 463 .

14 Alm. MK. tatbikat K. maddə $17 \mathrm{fk}$. 4: Bir yabaneı kanununa dayanarak boşanmaya hükmedilmek için boşanmanın gerek o yabancı kanuna ve gerek Alman kanunlarına göre caiz olması lâzımdır. Kezalik krş. : Bustamante Kodu madde 52.

15 Devletler hususi hukukuna dair 2. Ağustos 1926 tarihli kanun madde 7. Krs. Prof. Nusret Metya'nın talebe tarafından tntulan ders notları, Ankara Huhuk Fakültesi talebe cemiyeti neşriyatından, 1939, sahife 104. 
edilmekte idi $\left[{ }^{16}\right]$. Bu surećle Yunanlılar da tek başlarına tatbik etmekte oldukları lex fori esasınr brrakarak bütün devletlerce kabul edilmiş bulunan bir esasa katılmiş oluyorlar.

Aynî baklar da, yine genel olarak kabul edilmiş bir esas olan lex rei sitae kaidesine tâbi tutulmuşlardrr (madde 27). İster menkullere, ister gayrimenkullere taallûk etsin, bütün aynî haklar aynın bulunduğu yerin hukukuna tâbidir.

Lex rei sitae esasına miras bukukunda bir istisna kabul edilmiştir: bütün miras, menkul mirası, gayrimenkul mirası tefriki yapılmaksızın bir bütün olarak bir tek hukuka, yani murisin millî hukukuna tâbi tutulmuştur. Bu suretle Almanyada da yerleşmiş bullunan $\left[{ }^{17}\right]$ ve bizim sistemimizden ayrilan $\left[{ }^{18}\right]$, bir esas kabul edilmiş oluyor.

Çok ehemmiyetli bir madde de ânsme intizamı prensipini koyan 33 üncü maddedir. Bu madde 1856 tarihli kanunun 8 inci maddesinde esasen mevcut olan bir kaideyi tekrar etmiş bulunuyor.

Yuakrda verilen izahattan ve yeni Yunan Medeni Kanununun devletler hususi hukuku kaidelerinin tercümesinden de anlaşılacağı gibi, Yunan kanun koyucusu bütün devletler hususi hukuku meselelerini en ince teferruatına kadar tanzim etmek yoluna gitmemiş, artrk hemen hemen umumun da malı olmaya başlamıs bulunan genel bazı prensipleri tesbit etmekle iktifa ederek diğer hususların çözülmesini devletler hususi hukuku ilmine ve içtihatlara brrakmıştır. Yunan kanun koyucusu, hukukun bu çok güç ve karışık olan kısmını, en modern görüiş ve telâkkilere uygun olarak ve eşsiz bir muvaffakiyetle tanzim etmiştir. Bununla beraber asıl kanun ile Prof. Maridakis'in projesi mukayese edilecek olursa, projenin daha vazıh olduğu ve milletlerarası anlaşmalarla tesbit edilmiş bulunan esasları daha açı bir ifade ve katiyetle kabul etmekten çekinmediği görülür.

İster Medeni Kanunumuza ek olarak, ister mustakil bir kanun şeklinde olsun, bizde de kanunlar ihtilâfı kaidelerini sağlam temellere dayandırmak artık mübrem bir ihtiyaç haline gelmiştir. Kapitülâsyonların ilgası üzerine geçen Dünya Harbi içinde ve bilhassa başka mülâhazalarla çıarılan ve kanunlar ihtilâfına taallûk eden hükümleri bir tek mad-

16 29. Ekim 1856 tarihli kanun madde 6.

17 AlMK. tatbikat K. madde 25.

18 Bizim sistemimiz için bk: Muammer Raşit Seviğ, adı geçen eser cilt 1, sahife 394 vdd. 
de içine sıkıştırılmış bulunan bir kanunla bugünün ihtiyaçlarını gidermeye imkân yoktur. Yeni bir kanun hazırlıyabilmek için de uzun ve mukayeseli tetkiklere lüzum vardır. Şu halde ilk yapılacak iş devletler hususi hukuku kaynaklarını, yani bütün devletlerin kanunlar ihtilâfı kaidelerini ve bu husustaki milletlerarası anlaşma ve mukaveleleri sistemli bir şekilde toplamak ve bunları dilimize çevirmektir.

\title{
1941 TARİHLI YENI YUNAN MEDENI KANUNUNUN KANUNLAR IHTTILÂFI KAIDDELERI
}

\section{BIRINCI KITAP}

\author{
İkinci kısım
}

Madde 4. Yabancularm bali. eder.

Yerlilerin istifade ettiği medeni haklardan yabancılar da istifade

Madde 5. Medeni yeterlik.

Hakiki kişilerin medeni haklardan istifade yeterliği onların millî hukukuna göre tâyin edilir.

Madde 6. Gaiplik.

Gaiplik millî hukuka bağlıdır.

Yunan mahkemeleri, gaipliğinden önce Yunanistanda ikametgâhı veya konutu bulunan veyahut Yunanistanda bir servete malik olan yabancı hakkında da gaiplik kararı verebilirler.

Madde 7. Işlem yeterliği.

Bir kimsenin medeni hakları kullanma yeterliği (işlem yeterliği), onun millî hukukuna göre tâyin edilir.

Madde 8. Kısıt.

Kısıt millî hukuka bağlıdır.

Yunan mahkemeleri Yunanistanda ikametgâhr bulunan bir yabancr hakkında da kısit kararı verebilirler.

Yunanistanda konutu bulunan veya bir servete malik olan yabancı hakkında ancak geçici tedbirler alınabilir.

Madde 9. Yunanistanda yabancılarm yeterliği.

Yunanistanda bir işlem yapan yabancı, bağlı olduğu devlet hukukuna göre bu hususta ehil olmasa bile, Yunan hukukuna göre buna ehil 
ise, o işlemi yapmak hususunda ehil sayrlır.

Bu hüküm miras hukukuna ve yabancı memleketlerde bulunan gayrimenkullere taallûk èden işlemler hakkında uygulanmaz.

Madde 10. Hükmi şabıslar. (T'üzel kişiler).

Tüzel kişilerin yeterliği ikâmetgâhlarının bulunduğu yer hukukuna bağlıdır.

Madde 11. Isslemlerin şekilleri.

Bir hukuki işlemin şekli, esasın tâbi olduğu hukuka veya işlemin yapıldığı yerin hukukuna uygun olduğu takdirde, o işlem şekil bakımından muteberdir.

Madde 12.

Bir ayna taalluk eden hukuki işlemin şekli o şeyin bulunduğu yerin hukukuna bağlıdır.

Madde 13. Evlenmenin esash unsurlari.

Evlenmenin esaslı unsurları tisşanlılardan her birinin millî hukukuna bağlıdır.

Madde 14. Kan ve kocanın şabsi münasebetleri.

Karı ve kocanın şahsi münasebetleri evlilik esnasındaki son müşterek uyruklukları hukukuna, müşterek uyrukluklarr yoksa, kocanın evlenme anında uyruğu bulunduğu devletin hukukuna bağlıdır.

Madde 15. Karı ve kocanin malì münasebetleri.

Karı ve kocanın malî münasebetleri, kocanın evlenme akdi anındaki millî hukukuna bağlıdır.

Madde 16. Boşanma.

Boşanma ve ayrılık, eşlerin mahkemeye müracaattan evvel ve evlilik esnasındaki son müşterek uyruklukları hukukuna bağlıdır.

Müşterek uyruklukları yoksa, kocanın evlenme akdi anındaki millî hukuku nazarı itibara alınır.

Madde 17. Sabih neseb.

Bir çocuğun nesebinin sıhhatı, ananın kocasının doğum anındaki millî hukukuna göre tâyin olunur.

Çocuk evliliğin zevalinden sonra doğmuş olursa, çocuğun nesebi- 
nin srhhati, ananın boşanma anındaki kocasının millî hukukuna bağlıdır.

Madde 18. Çocuk ile ana arasindaki münasebetler.

Ana baba ile çocukları arasındaki münasebetler baba ile çocuğun son müşterek millî hukuklarına, müşterek uyruklukta değilseler babanın çocuğun doğumu anındaki millî hukukuna bağlıdır.

Babanın ölümü halinde bu münasebetler, ana ile çocuğun babanın ölümünden sonraki müşterek millî hukuklarına, böyle müşterek hukuk yoksa ananın, babanın ölümü anındaki millî hukukuna bağlıdır.

Madde 19. Nesebi sabib olmıyan çocuk.

Evlilik dişında doğan bir çocuk (nesebi sahih olmryan bir çocuk) ile anası arasındaki münasebetler ana ve çocuğun son müşterek millî hukuklarına, müşterek uyruklukta değilseler, ananın doğum anındaki millî hukukuna bağlıdir.

Madde 20.

Evlilik dışında doğan çocuk ile tabî̂ babası arasındaki münasebetler, çocuğun tabiî̀ babasının doğum anındaki millî hukukuna bağlıdır.

Madde 21.

Evvlilik dişındaki baba ile çocuğun anası arasındaki münasebetler ananın, çocuğun doğumu anında tâbi olduğu devletin hukukuna göre tâyin edilir.

\section{Madde 22. Nesebin tashibi.}

Nesebin tashihi, babanın, tashih anındaki millî hukukuna veya baba daha önce ölmüş bulunursa, ölümü anındaki millî hukukuna bağlıdır.

\section{Madde 23. Evlât edinme.}

Evlât edinmenin esaslı unsurlarr taraflardan her birinin millî hukukuna bağlıdrr.

Evlât edinen ile evlâtlık arasındaki münasebetler tarafların evlât edinme anındaki müşterek millî hukukuna bağlıdır. Uyruklukları müşłerek değilse, evlât edinenin, evlât edinme anındaki millî hukukuna bağlidir.

\section{Madde 24. Himaye ve yardim.}

Vesayet ve diğer her hangi bir himaye ve yardım o kimsenin uyruğu bulunduğu devletin hukukuna bağlıdir.

Yunan mahkemeleri Yunanistanda ikametgâhı bulunan bir yabancrya da bir vasi veya bir kayım tâyin edebilirler. Yabancinın Yunanistan- 
da sadece bir konut veya serveti bulunursa, ancak geçici tedbirler alinabilir.

Madde 25. Akitten doğan borçlar.

Akitten doğan borçlar, taraflarını tâbi kıldrkları hukuka bağlıdır.

Madde 26. Haksız fiillerden (eylemlerden) doğan borçlar.

Haksız eylemlerden doğan borçlar, eylemin vuku bulduğun yerin hukukuna bağlıdrr.

Madde 27. Zilyetlik, aynî baklar.

Zilyetlik ve menkul ile gayrimenkuller üzerindeki aynî haklar, aynin bulunduğu yerin hukukuna bağlrdrr.

\section{Madde 28. Miras.}

Mirasa mütaallik münasebetler müteveffanın, ölümü anındaki millî hukukuna bağlıdır.

Madde 29. Uyrukluğun iktisabı ve ziyar.

Bir devletin uyrukluğunun iktisabı ve ziyar, o devletin hukukuna bağlidır.

Madde 30. Uyruksuzluk.

Bir kimse hiçbir devletin uyrukluğunda bulunmazsa, uyrukluk hukuku yerine ikametgâhının bulunduğu yerin, ikametgâhı da yoksa koolduğu memleketin hukuku uygulanır.

Madde 31. Çok uyrukluluk.

Yabancı bir uyruklukla Yunan uyrukluğunun birleşmesi halinde Yunan hukuku uygulanir.

Bir kimse birden çok yabancr uyrukluğu haiz olursa, en fzala bağlı olduğu memleketin hukuku uygulanır.

Madde 32. Atuf.

Yabancı hukukun tatbikı lâzım gelen hallerde o devletin devletler hususi hukuku kaideleri nazarı itibara alınmaz.

Madde 33. Amme intizamı.

Âdap ve ahlâka ve umumiyetle âmme intizamının aykırı olan yabancr hukuk hükümleri uygulanmaz. 


\section{TASARI [*]}

Madde 11 - Şahsiyetin başlangicı ve sonu her şahsın bağlı olduğu devletin hukukuna (millî hukuka) göre tâyin olunur.

Madde 12 - Gaiplik kararı şahsın bağlı olduğu devletin hukukuna göre verilir.

Gaiplik kararı ancak gaibin bağlı olduğu devletin mahkemeleri tarafından verilebilir.

Bir yabancı hakkında Yunan mahkemeleri tarafindan ve Yunan hukukuna göre ancak Yunan hukukuna tâbi olan hukuk münasebetleri ve Yunanistanda bulunan mameleki hakkında hüküm ifade edecek ssekilde veya gaibin Yunan uyrukluğunda bulunan veya evlenmeden önce Yunan uyrukluğunda bulunmuş olan karısı tarafından talep edildiği takdirde gaiplik kararı verilebilir.

Madde 13 - Bir kimsenin medeni hakları kullanma yeterliği (işlem yeterliği) o kimsenin bağlı olduğu devlet hukukuna göre tâyin olunur.

Medeni hakları kullanma yeterliği bir kere iktisap edilmekle uyrukluk değisstirilmesi halinde de devam eder.

Maded 14 - Yunanistanda borçlar hukuku çevresine giren bir işlemi yapan yabancı Yunan kanunlarına göre medeni haklarını kullanmak yeterliğini haiz olursa, o işlem bakımından işlem yapmaya ehil sayilır.

Madde 15 - Bir kimsenin hacrı (kısıtr) onun bağlı olduğu devletin hukukuna bağlrdır.

Bir kimsenin kısıtına yalnız onun bağlı olduğu devletin mahkemeleri karar verebilir.

Bir kimsenin bağlı olduğu devlet hukukuna göre bir kısıt sebebi mevcut olursa, ikametgâhr veya konutu Yunanistanda bulunan yabancının korunması için geçici tedbirler alınabilir. Gerek Yunan hukuku,

* Mukayese imkânını vermiş olmak için yeni Yunan Medeni Kanununun devletler hususi hukukuna aid kısmının Profesör Maridakis tarafından kaleme alınmış olan tasarısının tercümesini de ilâve ediyoruz. 
gerek o kimsenin bağlı olduğu devlet hukuku tarafından kısıt sebebi olarak kabul edilen bir sebep mevcut olduğu takdirde her iki hukuka göre hakkx olan kimselerin talebi üzerine icabrnda Yunanistanda da bir yabannun kisıtına karar vrilebilir.

Madde 16 - Yabancı tüzel kişiler, yeterlikleri kıral emirnamesiyle kabul edilmek şartiyle, Yunanistanda da medeni haklardan istifade ve onları kullanma yeterliğini haiz sayılırlar.

Madde 17 - Bir hukuki işlemin şekli esas hakkında cari olan hukuka veya hukuki işlemin yapıldiğı yer hukukuna yahut âkitlerin millî hukukuna uygun olduğu takdirde, o hukuki işlem şekil bakımindan muteber sayılir.

Aynî bir hak ihdasına, nakline veya refine yarıyan bir hukuki işlemin şekli, aynın bulunduğu yer hukukuna bağlıdır.

Madde. 18 - Evlenme hakkında nişanlılardan her birinin tâbi olduğu devletin hukuku uygulanır.

Madde 19 - Karı ve kocanın şahsi münasebetleri onların millî hukukuna bağlıdır.

Karı ve koca ayni uyruklukta bulunmamış olur veya müşterek uyrukluğu kendi rrzalariyle edinmiş olmazlarsa, evlenme sırasında kocanın bağlr olduğu devletin hukuku uygulanır.

Madde 20 - Karı kocanın malî münasebetleri kocanın evlenme akdi sırasındaki millî hukukuna bağlı olur.

Gayrimenkullerin bulunduğu yer hukukuna göre o hukukun uygulanması lâzım gelen hallerde kocanın millî hukuku uygulanmaz.

Madde 21 - Boşanma hukuku, boşanma sebebi olarak ileri sürülen hâdisenin vuku bulduğu ânda karının millî hukukuna ve ayni zamanda da kocanın millî hukukuna bağlı olur.

Gerek karı kocanın millî hukuklarına gerek Yunan hukukuna göre bir boşanma sebebi bulunmadıkça boşanmaya hüküm olunamaz.

Madde 23 - Bir çocuğun nesebinin sthhati ananın kocasının doğum ânindaki millî hukukuna göre tâyin olunur.

Doğum ânında evlilik mevcut olmazsa çocuğun nesebinin sshhati evlenmenin nihayet bulduğu ânda ananın kocasının millî hukukuna göre tâyin olunur. 
Madde 23 - Ana baba ile çocukları arasındaki münasebetler baba ile çocuğun son müşterek uyruklukları hukukuna veya baba doğumdan önce ölmüş olursa, ana ile çocuğun müşterek uyrukluklan hukukuna ve müşterek uyruklukları bulunmaması halinde çocuğun millî hukukuna bağlıdır.

Gayrimenkullerin bulunduğu devlet kendi hukukunun tatbikını âmir ise gayrimenkuller hakkında millî hukuk uygulanmaz. gulanmaz.

Millî hukuk kızın kocasının hukuku ile taarruz ettiği nispette uy-

Madde 24 - Nesebin tashihi, babanın tashih ânındaki millî hukuna bağlıdır.

Nesebin tashihinde çocuğun şahsı bakımından aranan şartlar onun milî hukukuna göre tâyin olunur.

Maddè 25 - Evlât edinme hakkında evlât edinenin tâbi olduğu devletin hukuku uygulanir.

Evlât edinmede evlâtlı̆̆ın şahsı bakımından aranan şartlar onun millî hukukuna göre tâyin olunur.

Madde 26 - Nesebi sahih olmıyan (evlilik dışında doğan) bir çocuğun anasiyle olan münasebetleri ana ve çocuğun doğum ânındaki müşterek uyrukluklarına göre tâyin olunur. Müşterek uyruklukları yoksa çocuk için daha elverişli olan hukuk uygulanır.

Şahsi hallere mütaallik münasebetler ananın doğum ânındaki millî hukukuna göre tâyin edilir.

Ayni hukuk nesebi sahih olmıyan çocuğun, anasının hısımlariyle olan münasebetleri hakkında uygulanir.

Madde 27 - Nesebi sahih olmiyan bir çocuk ile onun tabiî babası arasındaki hukuki münasebetler çocuğun, doğum anında tâbi olduğu devletin hukukuna göre tâyin olunur. Çocuğun tabî̂ babası Yunan uyrukluğunda ise Yunan hukukuna göre tanınan haklardan fazlası istenmez.

Nesebi sahih olmıyan çocuk ile tabî̀ babası arasındaki şahsi münasebetler çocuğun tabî̀ babasının doğum anında tâbi olduğu devletin hukukuna göre tâyin edilir. Aynı hukuk nesebi sahih olmıyan çocuk ile tabiî babasının hısımları arasındaki münasebetlere de uygulanır. 
Madde 28 - Evlilik dışındaki baba ile ana arasındaki hukuki münasebetler ananın çocuğun doğumu zamanında tâbi olduğu devletin hukukuna göre tâyin edilir.

Baba Yunan uyrukluğunda ise Yunan hukukuna göre tanınan haklardan ziyadesi istenemez.

Madde 29 - Vesayet ve diğer her hangi bir himaye ve yardım o kimsenin tâbi olduğu devletin hukukuna bağlıdır.

İkametgâhı've konutu Yunanistanda bulunan bir yabancının bağli olduğu memlekette himaye tedbirleri alınmadığı takdirde o yabanc1 vesayet altına alınabilir veya başka suretle himaye ve yardım görür.

Madde 30 - Akitlerden doğan borç münasebetleri, hükümleri bakımından tarafların bağlı tuttukları hukuka bağlıdırlar.

Taraflar uygulanması lâzımgelen hukuku göstermedikleri takdirde halin icaplarına göre, borç münasebeti için en elverişli olan hukuk uygulanir.

Bir akdin inikadı için lüzumlu şartlar akdin yapıldığı devletin hukukuna göre tâyin olunur.

Madde 31 - Haksız eylemden doğan borçlar haksız eylemin vuku bulduğu devletin hukukuna bağlıdır.

Madde 32 - Zillyetlik, mülkiyet ve menkul ile gayrimenkuller üzerindeki sair haklar, aynın bulunduğu yer hukukuna bağlıdır.

Madde 33 - Mirasın intikali, terekeye dahil malların mahiyeti veya bulundukları yer nazarı itibara alınmaksızın, murisin millî hukukuna bağlıdır.

Gayrimenkullerin bulunduğu yerin hukuku o yer hukukunun uygulanmasınx âmirse, murisin millî hukuku uygulanmaz.

Madde 34 - Bir kimse hiçbir devletin uyrukluğunda bulunmazsa ikametgâhının bulunduğu yerin, ikametgâhı da yoksa konutunun bulunduğu yerin hukuku tatbik olunur.

Madde 35 - Yabancı bir uyruklukla Yunan uyrukluğunun birleşmesi halinde Yunan hukuku uygulanır.

Birden çok yabancı uyrukluğun birleşmesi halinde o şahsın açı olarak uyrukluğunu tercih ettiği devletin hukuku uygulanır. 
Madde 36 - Bir kimsenin bir devletin uyrukluğunda olup olmadığı o devletin hukukuna göre tâyin olunur.

Madde 37 - Yukarkki hükümler mucibince bir hukukun uygulanması lâzımgelen hallerde o hukuk nizamının kanunlar ihtilâfı kaideleri değil, esas hakkındaki hükümleri uygulanır.

Madde 38 - Yunan yargıcı âdap ve ahlâka ve âmme intizamına aykurı olan yabancr hukuku hiçbir zaman uyguluyamaz. eder.

Madde 39 - Yabancı da bir Yunanlı gibi özel haklardan istifade

Madde 40 - Bir yabancı devlet Yunan uyruklarına kendi veya üçüncü bir devletin uyruklarından daha kötü muamele ettiği takdirde, daha önce Nazırlar Meclisinin de muvafakati alınmak şartiyle, kıral nizamnamesiyle o yabancı devlete ve onun uyruklarına ve haleflerine karşı misliyle mukabele edilebilir.

\section{Seni sitmadan kurtaracak olanla beraber ol.}

